\title{
Validation of a Nonlinear Two-dimensional MacPherson Suspension System Model with Multibody Simulations
}

\author{
Atte Rankinen \\ Mechatronics and machine diagnostics \\ Faculty of technology \\ P.O. Box 4200 FI-90014 \\ University of Oulu, Finland \\ Email: atte.rankinen@oulu.fi
}

\author{
Enso Ikonen \\ Systems Engineering \\ Faculty of technology \\ P.O. Box 4200 FI-90014 \\ University of Oulu, Finland \\ Email: enso.ikonen@oulu.fi
}

\author{
Toni Liedes \\ Mechatronics and machine diagnostics \\ Faculty of technology \\ P.O. Box 4200 FI-90014 \\ University of Oulu, Finland \\ Email: toni.liedes@oulu.fi
}

\begin{abstract}
This paper studies the possibility to use a simplified MacPherson suspension system model for tuning active suspension system controllers. With a nonlinear suspension model, more accurate responses can be obtained compared to a traditional linear quarter-car suspension system model. The presented nonlinear two-dimensional mathematical model for the MacPherson suspension system is simulated in MATLAB/Simulink and validated by comparing it to an Adams/View multibody model with three simulation cases, one for kinematic analysis and two for dynamic analysis. The results are expressed as normalized RMS deviation values between the outputs of the two models. Most outputs of the two models go hand in hand, and the greatest difference is in the camber angle values derived from simplified linearization in the mathematical model.
\end{abstract}

Index Terms-suspension system simulation, multibody system, vehicle dynamics, MacPherson suspension

\section{INTRODUCTION}

A suspension system plays an important role in vehicle systems [1], [2], mainly providing vehicle handling with increased controllability and improved traction and roll stability, while also increasing the ride comfort of the passengers. In suspension systems good vehicle handling and ride comfort can be contradictory, because better handling performance does not typically equal comfortable ride.

The MacPherson suspension is commonly used in small and mid-sized vehicles, mainly in the front [3]. The MacPherson suspension is a simple, compact sized and low weight structure. Its disadvantages compared to different suspension structures (e.g. a double wishbone) are less favorable kinematic performance, higher demand in steering, increased tire wear and lesser isolation of the vehicle body from the road excitation input [4].

A wealth of nonlinear mathematical models for suspension systems have been reported in literature. Study [5] derived a complex nonlinear model of the MacPherson suspension system and compared it to a quarter-car and full car Adams/Car multibody model. The results showed better demonstration in the dynamic responses of the nonlinear model than a conventional linear quarter-car suspension model. In [6], a nonlinear model introduced in [3] was tested in an Adams/Car, and the use of the nonlinear model over a linear quarter-car suspension model was reasoned.

Mathematical MacPherson suspension system models have been applied in variety of studies. Study [7] applied semiactive $H_{\infty}$ control strategy to MacPherson suspension with hybrid control between a skyhook and groundhook algorithm. In [8], independent MacPherson suspension units were used in the two steering axles of a $8 \times 8$ vehicle Adams simulation model for optimizing the design of the steering system. In [9], an active composite nonlinear feedback control of MacPherson suspension and a conventional quarter car suspension system model were compared to a linear quadratic regulator control and a passive control.

In [10], [11] a simple nonlinear two-dimensional dynamic model of the MacPherson suspension system was derived by analyzing the system kinematics and deriving the dynamics using the Euler-Laurange approach [12], [3]. In [10], the work was extended to state estimation and control in a stochastic environment. The aim of this paper is to validate the twodimensional MacPherson model presented in [10] by comparing its outputs to similar two-dimensional model made in commercial multibody simulation software Adams/View. The dynamic behavior of the suspension system is simulated with sine wave and bump/pothole excitation. With this kind of validation, the use of a mathematical nonlinear MacPherson model could be justified for active suspension control design.

This paper is organized as follows. Section 2 will outline the kinematic and dynamic equations that are derived in [10]. Section 3 describes the two-dimensional multibody model prepared in Adams/View. Section 4 illustrates the performed simulations and results. Finally, the summary and conclusion section summarizes the main points and presents ideas for future work.

\section{MACPHERSON MODEL BACKGROUND}

Modeling the MacPherson suspension system in a twodimensional planar model can express the essential responses 


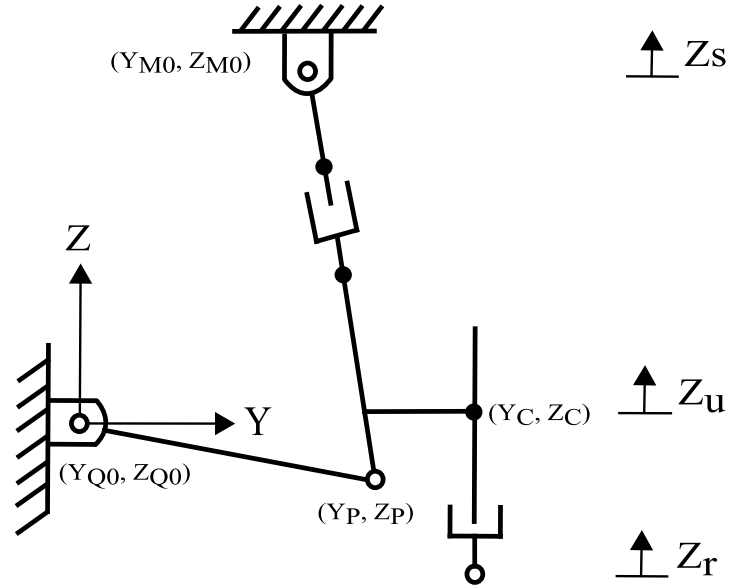

Fig. 1. Kinematic model.

of the system [3], [12]. The derivation of [10], [11] followed the path outlined in [12]. Figures of the model are adapted from [12] and shown in Fig. 1 and 2.

The following restrictions are considered for the model:

- Chassis body displacement only in vertical motion

- All parts are rigid

- Ideal joints

- The tire is modeled as a linear spring-damper

- Linear spring-dampers

- The chassis body and the tire have fixed masses, while other parts' masses are negligible

In [10], a simple nonlinear model was derived based on linearized kinematics of the planar system and the system dynamics were obtained from Euler-Lagrange equations:

$$
\begin{array}{r}
m_{s} \ddot{Z}_{s}+k_{C}^{2} m_{u}\left(\ddot{Z}_{s}-\ddot{Z}_{u}\right)+I_{C} k_{\phi}^{2}\left(\ddot{Z}_{s}-\ddot{Z}_{u}\right) \\
-K_{s} F_{K}\left(Z_{s}-Z_{u}\right)+K_{t l} k_{Y}^{2}\left(Z_{s}-Z_{u}\right) \\
+B_{s} F_{B}\left(\left(Z_{s}-Z_{u}\right),\left(\dot{Z}_{s}-\dot{Z}_{u}\right)\right)=0 \\
m_{u} \ddot{Z}_{u}-m_{u} k_{C}^{2}\left(\ddot{Z}_{s}-\ddot{Z}_{u}\right)-I_{C} k_{\phi}^{2}\left(\ddot{Z}_{s}-\ddot{Z}_{u}\right) \\
+K_{s} F_{K}\left(Z_{s}-Z_{u}\right)+B_{t}\left(\dot{Z}_{u}-\dot{Z}_{r}\right) \\
+K_{t}\left(Z_{u}-Z_{r}\right)-K_{t l} k_{Y}^{2}\left(Z_{s}-Z_{u}\right) \\
-B_{s} F_{B}\left(\left(Z_{s}-Z_{u}\right),\left(\dot{Z}_{s}-\dot{Z}_{u}\right)\right)=0
\end{array}
$$

where

$$
F_{K}(x)=\frac{k_{L} k_{\theta}\left(L_{03}-\sqrt{L_{03}^{2}+k_{L} k_{\theta} x}\right)}{2 \sqrt{L_{03}^{2}+k_{L} k_{\theta} x}}
$$

and

$$
F_{B}(x, y)=\frac{k_{L}^{2} k_{\theta}^{2} y}{4\left(L_{03}^{2}+k_{L} k_{\theta} x\right)}
$$

Camber angle is approximated as $\phi=k_{\phi}\left(Z_{s}-Z_{u}\right)$. The coefficients are $k_{C}=\gamma Z_{P 0}\left(Z_{P 0}-Z_{C 0}+L_{03}\right), k_{\theta}=\gamma L_{03}$

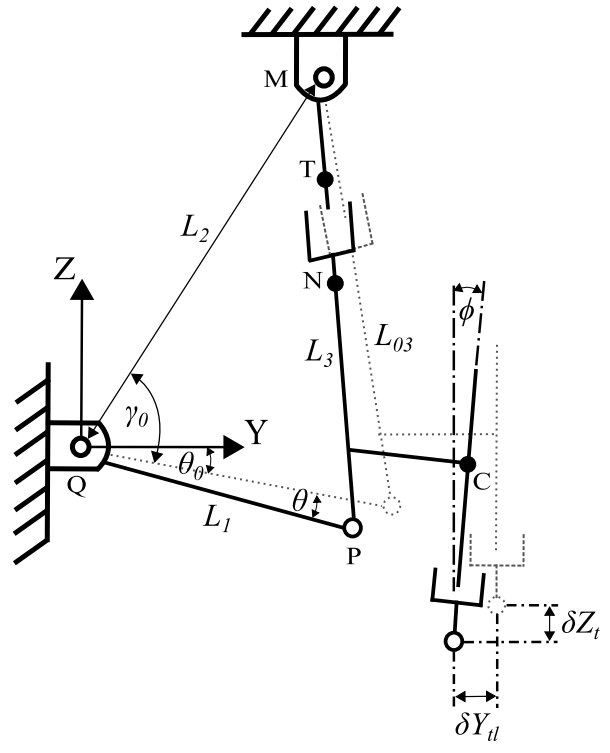

Fig. 2. Dynamic model.

and $k_{\phi}=-\gamma Z_{P 0}$ with $\gamma^{-1}=Y_{P 0} Z_{P 0}-Y_{C 0} Z_{P 0}+Y_{P 0} L_{03}$, $k_{L}=2\left(Y_{M 0} Z_{P 0}-Y_{P 0} Z_{M 0}\right)$ and $k_{Y}=k_{C}-k_{\phi} R$, and strut length $L_{03}=\sqrt{\left(Y_{M 0}-Y_{P 0}\right)^{2}+\left(Z_{M 0}-Z_{P 0}\right)^{2}}$.

Following [12], [14], the system parameters were chosen as: for sprung and unsprung masses $m_{s}=453 \mathrm{~kg}, m_{t}=71$ $\mathrm{kg}$; spring and damping coefficients: $K_{s}=17658 \mathrm{~N} / \mathrm{m}, B_{s}=$ $1950 \mathrm{Ns} / \mathrm{m}, K_{t}=183887 \mathrm{~N} / \mathrm{m}, K_{t l}=50000 \mathrm{~N} / \mathrm{m}, B_{t}=2500$ $\mathrm{Ns} / \mathrm{m}$; and tire radius and inertia $R=0.29 \mathrm{~m}$ and $I_{C}=0.021$ $\mathrm{kgm}^{2}$; and point locations: $Y_{C 0}=0.3721 \mathrm{~m}, Z_{C 0}=0.0275$ $\mathrm{m}, Y_{Q 0}=0.0000 \mathrm{~m}, Z_{Q 0}=0.0000 \mathrm{~m}, Y_{M 0}=0.1074 \mathrm{~m}$, $Z_{M 0}=0.5825 \mathrm{~m}, Y_{P 0}=0.2490 \mathrm{~m}, Z_{P 0}=-0.0608 \mathrm{~m}$.

\section{Multibody MOdeL}

The commercial Adams simulation software is considered a realistic simulator of multibody dynamics [3], [12] and is thus used to validate the mathematical MacPherson model derived in the previous chapter with two-dimensional multibody simulation model.

The main components of the MacPherson suspension are the lower control arm, the tie rod and the strut. The lower arm is attached to the body with a revolute joint and to the spindle with a spherical joint. The tie rod operates the steering control and the strut that contains a spring-damper is connected to the chassis body with sphere joint and with fixed connection to the spindle [13].

Fig. 3 illustrates the Adams/View model used. The outline is similar to the multibody model presented in [12], but in this case the Adams/View model has rotation joints instead of sphere joints. The chassis body is only allowed to move in the vertical direction, the control arm is connected with a rotational joint from both the ends and the strut is coupled to the chassis with a rotational joint. The flexible tire is modeled as a linear spring-damper in the vertical direction and a linear spring in the horizontal direction. 


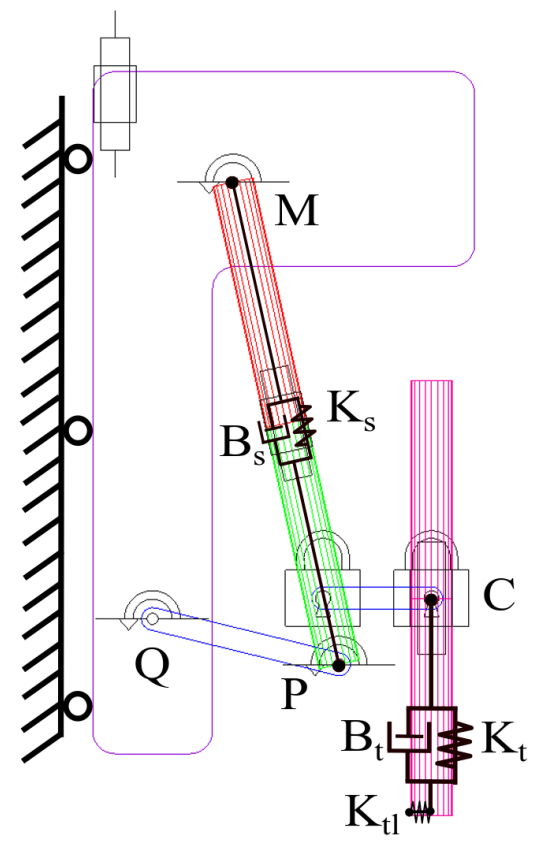

Fig. 3. Two-dimensional Adams/View model of MacPherson suspension (adapted from [12]).

\section{Simulations AND RESUlts}

The two simulation models were compared in three different cases presented below. The mathematical model was simulated in MATLAB/Simulink and the multibody model in Adams/View. The simulations were performed with a fixed time step of $1 \mathrm{~ms}$ for a simulation time of 10 seconds.

\section{A. Kinematic analysis}

Camber angle and wheel track width variation are compared to wheel center vertical displacement by fixing chassis movement $\left(Z_{s}=0\right)$ and using vertical displacement with input $0.1 \sin (2 \pi t)(\mathrm{m})[12],[3]$ to the wheel center. The results are shown in Fig. 4. There is a noticeable difference, as the [10] model is only producing linear results. This is due to simplifying the calculation of the $\phi$ (camber) angle. Also,

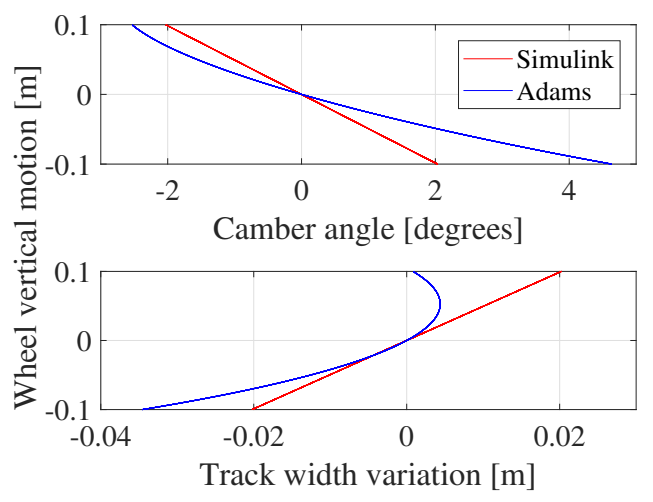

Fig. 4. Kinematic analysis similarities between the Adams/View model results with the model in [12] and in this paper can clearly be seen.

\section{B. Dynamic analysis}

The two dynamic analyses were performed by using a vertical road profile input to the bottom of the tire, and the chassis body is allowed to move in the vertical direction. RMS deviations of the simulation outputs divided by the mean absolute value of the Adams output are calculated from the results to express the difference as percentages.

1) Sinusoidal road profile: The road input used here is a sinusoidal wave $0.05 \sin (2 \pi t)(\mathrm{m})$. The results are shown in Fig. 5, 6 and 7. Displacement outputs are quite similar, though there is a slight difference in peak values and phase. In Fig. 7, the linearization of camber angle is emphasized as lower peak values in both directions. Nevertheless, for active suspension control design, the camber angle is not as important as the dynamic behavior of unsprung and sprung masses, which in this simulation case are almost identical.

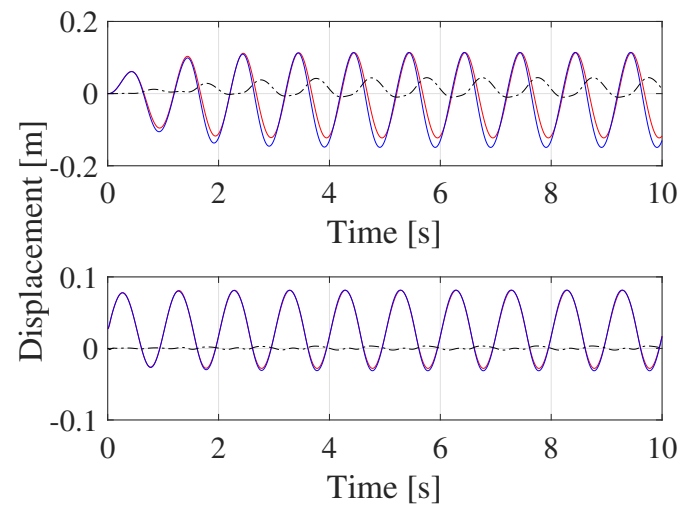

Fig. 5. Chassis displacement (upper) and wheel vertical displacement (lower).

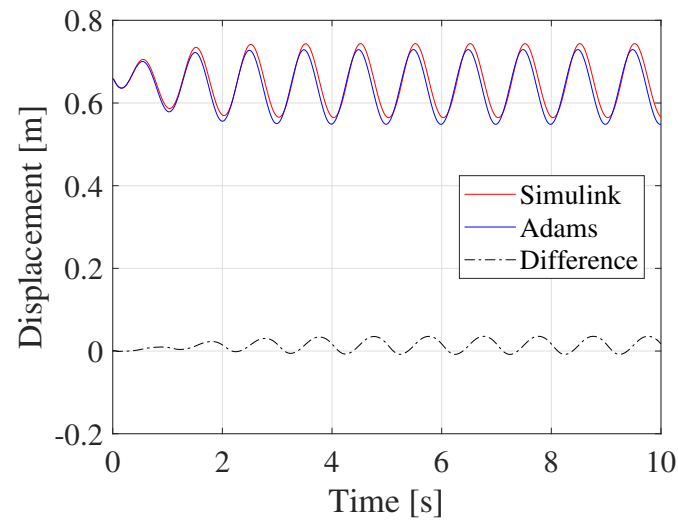

Fig. 6. Strut length.

2) Bump and pothole: The road profile used here is the same as in [11]: $100 \mathrm{~mm}$ road bump at $t=1 \mathrm{~s}$ and $100 \mathrm{~mm}$ pothole at $t=5 \mathrm{~s}$. As observed in previous simulation cases, the results (Fig. 8, 9, 10, 11, 12, 13) follow each other quite closely. With camber angle, the peak values are far greater in the Adams/View model than in the Simulink model. 


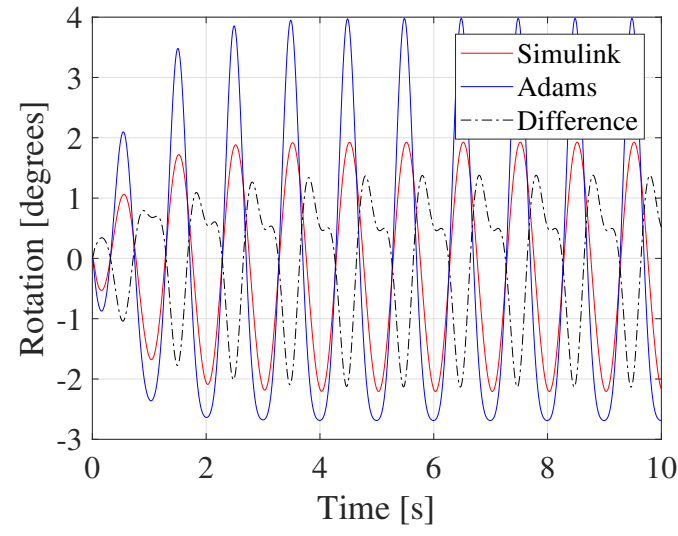

Fig. 7. $\phi$ (camber) angle.

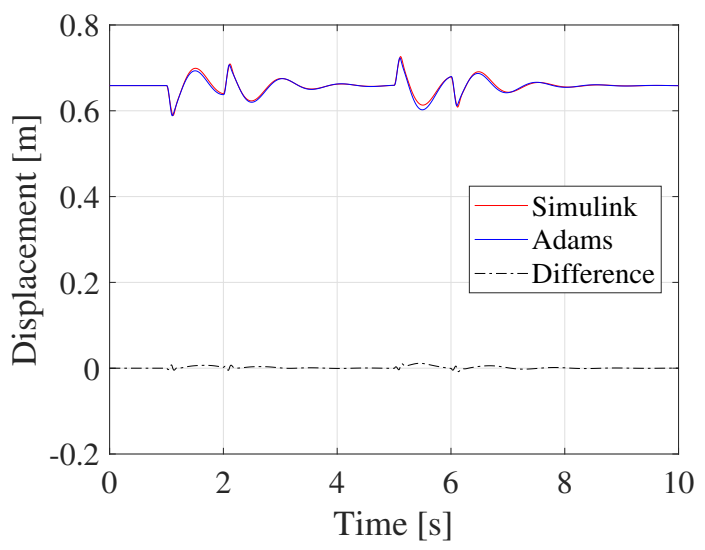

Fig. 8. Strut length.

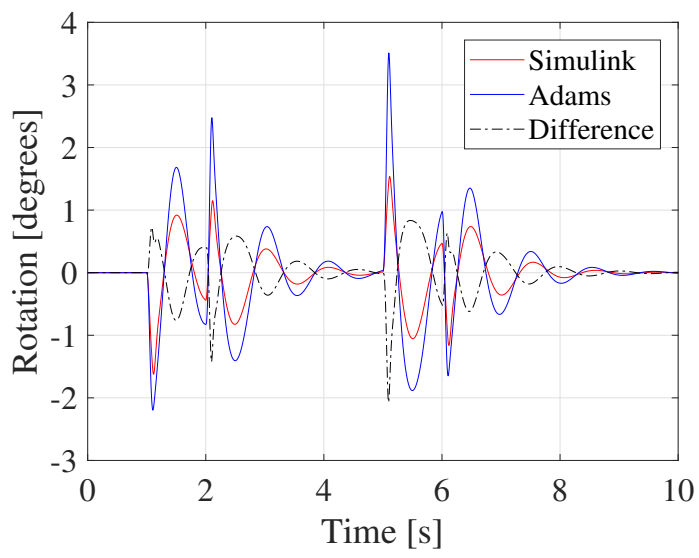

Fig. 9. $\phi$ (camber) angle.

\section{Results}

In Table I, small differences in the bump and pothole cases result from excitation being zero for most of the simulation time. The largest differences in percentages are with angles $\theta$, $\phi$ and the displacement of chassis $\left(Z_{Q}\right)$. When comparing the presented Adams model to a conventional linear quarter car model, the corresponding chassis displacement RMS deviation rates for $100 \mathrm{~mm}$ bump and $50 \mathrm{~mm}$ sine wave excitations

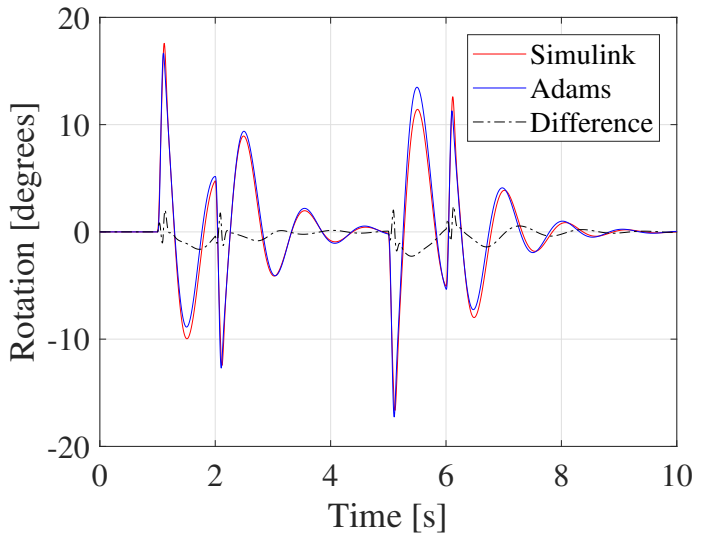

Fig. 10. $\theta$ angle.

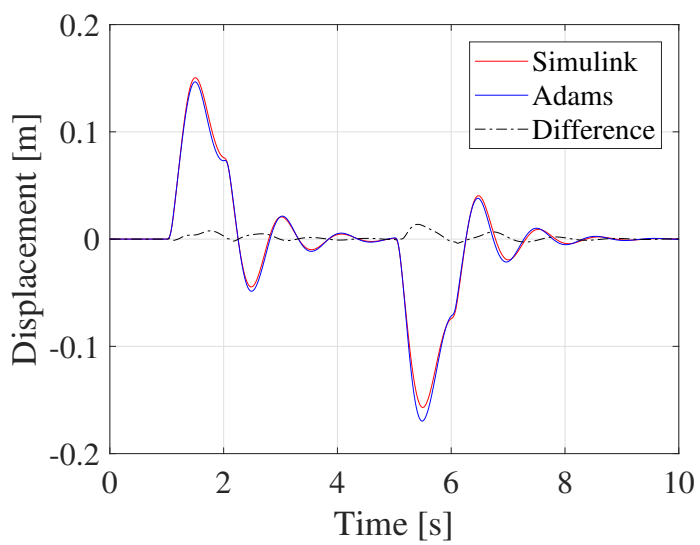

Fig. 11. Chassis $\left(Z_{Q}\right)$ displacement.

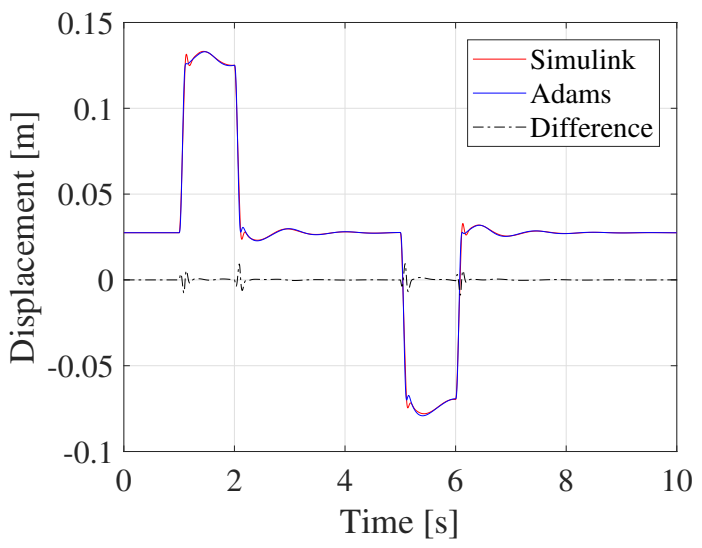

Fig. 12. Wheel center vertical $\left(Z_{C}\right)$ displacement.

are $21.9 \%$ and $39.1 \%$, respectively. From the results, it can concluded that the nonlinear mathematical model can be hypothesized as a simplified two-dimensional MacPherson suspension model with reservations.

\section{SUMmary AND DISCUSSION}

A nonlinear two-dimensional mathematical MacPherson suspension model [10] and a two-dimensional multibody 


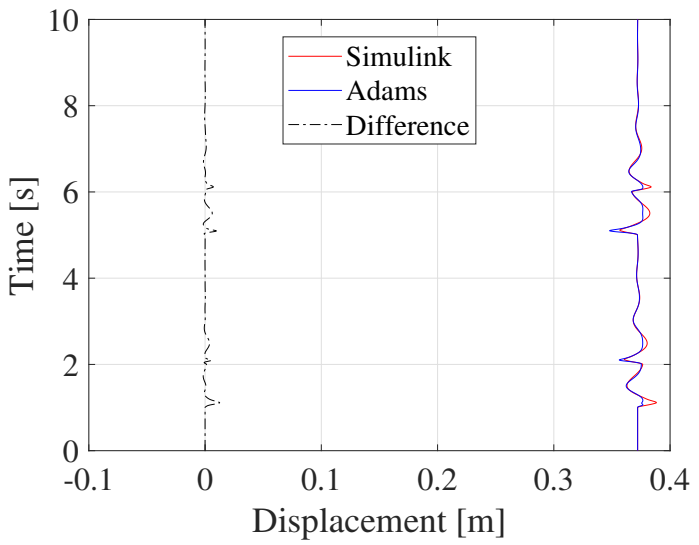

Fig. 13. Wheel center horizontal $\left(Y_{C}\right)$ displacement.

TABLE I

NORMALIZED RMS DEVIATIONS OF SIMULATION OUTPUTS

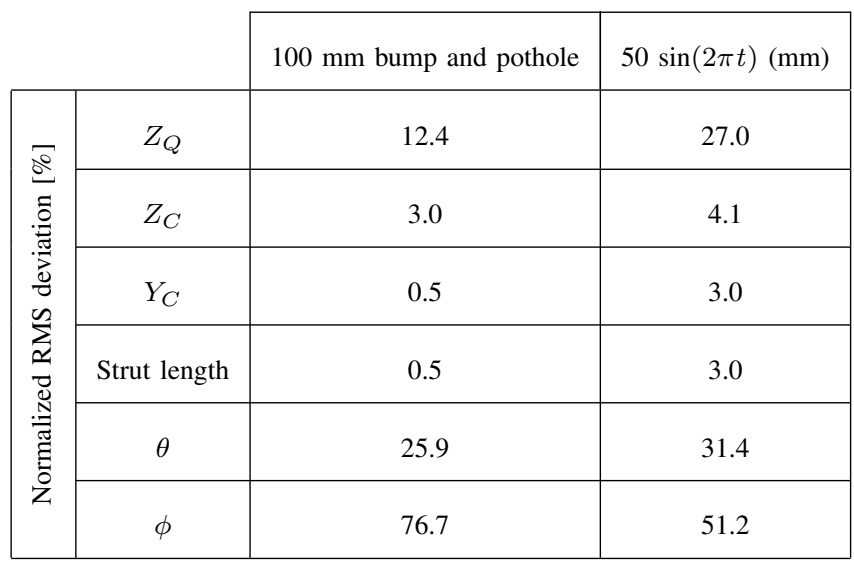

Adams/View model were investigated with three simulation cases. Similarities were noticed in most of the output values. Most of the differences are in the wheel camber angle that was obtained from simplifications in the calculations. For vehicle systems, changes in camber angle cause tire wear and affect vehicle steering, due to the lateral forces acting on the wheel [6].

The mathematical model is based on a model presented in [12], but in a simplified form, targeting it for simulation-based nonlinear control design. In this paper, the model is validated using the Adams/View multibody model. The similarities in dynamic responses qualify this model to be used in active suspension system control design. Even though the Adams/View model can be used for active suspension control design with Simulink co-simulation, the simulation times can be excessive and prevent model/simulation-based design control and state estimation approaches.

The main contribution of the paper is in that the model developed in [10] is validated against well-known and commonly accepted Adams simulations. The results show good performance, although the model equation simplifications show in the poor reproduction of the camber angle. The camber angle is, however, less significant in applications of active suspension control [10], [11], where the fast simulation speed of the proposed model can be exploited in simulation-based control design.

In future work, active suspension control design with Markov decision processes in [10], [11] can be further investigated, with different kinds of controller cost functions and road profile excitations.

\section{REFERENCES}

[1] J. Cao, H. Liu, P. Li, D.J. Brown, "State of the art in vehicle active suspension adaptive control systems based on intelligent methodologies", IEEE Transactions on intelligent transportation systems, vol. 9, no. 3, pp. 392-405, 2008.

[2] H. Tseng and D. Hrovat, "State of the art survey: active and semi-active suspension control", Vehicle System Dynamics, vol. 53, no. 7, pp. 10341062, 2015.

[3] M.S. Fallah, R. Bhat and W.F. Xie, "New nonlinear model of macpherson suspension system for ride control applications", Vehicle System Dynamics, vol. 47, no. 2, pp. 195-220, 2009.

[4] K.P. Balike, S. Rakheja and I. Stiharu, "Development of kineto-dynamic quarter-car model for synthesis of a double wishbone suspension", Vehicle System Dynamics, vol. 49, no. 1-2, pp. 107-128, 2011.

[5] C.C. Yu, C.C. Chiu, "Ride responses of macpherson suspension systems", MATEC Web of Conferences, vol. 123, 2017.

[6] M.H. Shojaeefard, A. Khalkhali and S. Yarmohammadisatri, "An efficient sensitivity analysis method for modified geometry of Macpherson suspension based on Pearson correlation coefficient", Vehicle System Dynamics, vol. 55, no. 6, pp. 827-852, 2017.

[7] H-H. Chiang, L-W. Lee, "Optimized Virtual Model Reference Control for Ride and Handling Performance-Oriented Semiactive Suspension Systems", IEEE Transactions on Vehicular Technology, vol. 64, no. 5, pp. 1679-1690, 2015.

[8] L. Li, C. Zhang, Z. Wang, M. Liu, J. Shi, "Motion Simulation and Optimization Design of Double-Front Axle Steering System Based on ADAMS", IEEE Conference and Expo Transportation Electrification Asia-Pacific, 2014.

[9] M.F. Ismail, Y.M. Sam, K. Peng, M.K. Aripin, N. Hamzah, ”A Control Performance of Linear Model and the MacPherson Model for Active Suspension System Using Composite Nonlinear Feedback", IEEE International Conference on Control System, Computing and Engineering, 2012.

[10] E. Ikonen, "Active suspension control with state estimation using finite Markov chains", Int. J. of Advanced Mechatronic Systems, vol. 7, No.3, pp.183 - 192, 2017.

[11] E. Ikonen, K. Najim and A. Garca-Cerezo, "MacPherson suspension system modeling and control with MDP", IEEE Symposium Series on Computational Intelligence (SSCI), 2016.

[12] J. Hurel, A. Mandow and A. Garcia-Gerezo, "Kinematic and dynamic analysis of the McPherson suspension with a planar quarter-car model", Vehicle System Dynamics, vol. 51, no. 9, pp. 1422-1437, 2013.

[13] Y.A. Papegay, J-P. Merlet and D. Daney, "Exact kinematics analysis of Car's suspension mechanisms using symbolic computation and interval analysis", Mechanism and Machine Theory, no. 40, pp. 395-413, 2004.

[14] H-C. Sohn, K-S. Hong, and J.K. Hedrick, "Semi-active control of the Macpherson suspension system: Hardware-in-the-loop simulations", Int. Conf. on Control Applications, IEEE, 2000. 